\title{
Editorial
}

\section{How times have changed for the revenue management professional!}

Twenty years ago, virtually no one would have thought that such a title would apply to their career. I can think of, at most, a few of my colleagues at American Airlines and several other airlines for whom such a title would have been apt, but they would likely have laughed it off at that point. The number of universities offering courses in revenue management could be counted on one hand, with fingers to spare. And while it might require the use of both hands, you probably still wouldn't need your toes to count the number of published papers on revenue management. Outside of the airline industry, revenue management (or yield management as it was then called) was virtually unknown.

What about today? Companies in many industries (not just travel) have revenue management departments or have created staff positions with revenue management in the title. Universities throughout the world are offering courses in revenue management, and numerous students are writing Masters and $\mathrm{PhD}$ theses on the subject. The first book providing a comprehensive view on both the theory and practice of revenue management, by Talluri and van Ryzin, was recently published. Once an area dominated by practitioners, who also engaged in research, there are now more and more researchers, some of whom also engage in practice. The number of students and faculty attending the 4th Annual Conference of the Revenue Management and Pricing INFORMS Section, in 2004, was far greater than the number of industry practitioners. Approximately 50 papers on the subject of revenue management were presented at the annual INFORMS conference in October 2004. Scarcely a month goes by without a revenue management conference taking place somewhere in the world. And, of course, revenue management professionals have now had a journal designed to meet their specific needs and interests for over four years.

As revenue management has grown, so too has the range of topics on which revenue management professionals focus. This special issue of the Journal reflects that growth. The range of ideas and methods covered in the papers in this issue are so great that I suspect there will be few readers of the Journal who will read this one 'cover to cover'. My hope is that there will be something for everyone.

In an effort to please everyone, and I hope many will regard it as a special revenue management treat, this issue contains a reprint of Kenneth Littlewood's seminal and oft-referred to paper, 'Forecasting and control of passenger bookings'. This paper was first published as part of the AGIFORS Proceedings in 1972 when Littlewood worked for the British Overseas Airways Corporation, and has won the 2004 Revenue Management and Pricing Section Historical Prize awarded by INFORMS. The paper, which contains the derivation for what has since become known as 'Littlewood's rule', was the first to consider why airlines would be better served financially by trying to maximise
Journal of Revenue and Pricing Management, Vol. 4, No. 2, 2005, pp. 109-110

C) Henry Stewart Publications, 1477-657X 
revenue rather than passengers on a flight, by limiting inventory availability based on fare paid. Littlewood blends both mathematical theory and practical issues in a relatively easy-to-read framework.

Two of the papers in this special issue come from strong mathematical backgrounds and may require a little patience and persistence, depending on how mathematically-minded you are. These are: 'Optimal pricing for variable volume outsourcing contracts' by Chris Kenyon; 'An evolutionary game-theoretic model of revenue management oligopolistic competition' by Terry L. Friesz, Reetabrata Mookherjee and Matthew A. Rigdon. These papers provide a sample of how far the theory of revenue management has evolved since its initial focus on airline or even travel company operations. For those readers who are not prepared to tackle these papers in their entirety, I suggest reading their introductions and motivating examples to get a flavour of the issues they address.

The paper by Warren H. Lieberman and Michael Raskin, 'Comparable challenges: A new approach to performance measurement', focuses on estimating the impact of revenue management decisions. The methodology they propose can be applied across industries and even beyond revenue management. Examples are drawn from outside the travel industry where tactical and strategic pricing are key; again demonstrating how far the field of revenue management has evolved.

In addition to the special issue papers we have a paper by Jamie Allsopp, 'Premium pricing: Understanding the value of premium', which discusses consumer behaviour issues in the area of premium pricing. With its focus on pricing and the importance of understanding customer purchasing desires and habits, the paper also highlights how far revenue management has evolved from its early focus on reservation inventory controls. It is good to see, however, that the airline industry could not be totally avoided in the paper and merits a brief paragraph.

The paper by Yang Dai, Robert Raeside, and Austin Smyth, 'The use of load factors to segment airline operators' ensures that we do not forget that airlines still play a major role in revenue management. The analytical methods employed in this paper, and the issues they deal with, highlight the diversification of revenue management, even within the airline industry.

Perhaps it is only fitting, then, that the futures paper in this special issue should be written by Garrett J. van Ryzin. As one of the leaders in revenue management research and co-author of The Theory and Practice of Revenue Management, he is wellpositioned to consider the continuing evolution of revenue management. His paper does not disappoint, and I am sure you will find his thoughts on the potential value of customer-based modelling to be very thought-provoking.

In closing, my advice is to 'go for it'. Find the papers that are of interest to you. Read them. Think about them. Enjoy them. And when you have a chance, give some thought as to how you became a revenue management professional and how you can influence the evolution of this discipline.

\section{Warren Lieberman Editorial Board}

\section{Reference}

Talluri, K.T. and van Ryzin, G.J. (2004) The Theory and Practice of Revenue Management, Kluwer Academic Publishers, Boston. 